\title{
Prolog: Szenen aus dem Leben als Organisationsberaterin, Autorin und Forscherin
}

Andrea Heistinger

Es ist Mitte Jänner des Jahres 2020. Bevor ich mich in meine Schreibklausur aufmache, um die Ergebnisse meiner Forschung zu Papier zu bringen - denn zu Hause neben meinen Kindern hat mein Schreiben keinen Platz - gehe ich noch einkaufen am Bauernmarkt in St. Pölten und auf einen Cappuccino in das Café, in dem ich auch immer wieder schreibe. Am Markt treffe ich auf Heidemarie ${ }^{1}$, die Blumenfrau. Sie sagt, sie hätte etwas für mich und holt eine kleine Flasche hervor, in die sie eine einzelne Tulpe gemeinsam mit Weidenzweigen arrangiert hat. Ein kleiner Brief hängt daran. Sie wünsche mir alles Gute beim Schreiben und die Blume möge mich bestärken. Offenbar hat sie schon damit gerechnet, dass ich heute vorbeikomme. Ich bin gerührt. Heidemarie kennt und schätzt meine Bücher. Letzte Woche hatte ich ihr erzählt, dass ich einen Buchbeitrag schreiben müsse und dass mir das viel leichter fallen würde, wenn auch nur eine Blume am Schreibtisch stünde. Gerade ist Rosemarie die einzige Blumenfrau in der Innenstadt von St. Pölten. Seit Anfang des Jahres steht sie nun einen Tag mehr pro Woche mit ihrem Stand am Herrenplatz. Sie fragt mich, ob ich Fotos von ihr in einigen Gruppen der Sozialen Netzwerke der Stadt posten

1 Alle Namen von Gesprächspartner*innen in diesem Forschungsprojektes wurden anonymisiert. 
könne, um die Menschen in der Stadt darüber zu informieren, dass sie nun auch freitags hier sei.

Im Café überfliege ich die Tageszeitungen. An dem Artikel in der Süddeutschen bleibt mein Blick hängen. Mit »Die Entfremdung« ist ein Artikel über die gegenwärtige Lage der Landwirtschaft in Europa tituliert. Dabei geht es um die Entfremdung zwischen jenen Menschen, die Lebensmittel erzeugen und jenen Menschen, die diese essen. "Ein neuer Gesellschaftsvertrag ist nötig, um Bauern und Verbraucher zu versöhnen«, schreibt der Autor. ${ }^{2}$ Dem kann ich mich nur anschließen. Hoch an der Zeit, die Ergebnisse unseres Forschungsprojektes auf Papier zu bringen. Wir haben uns viele Gedanken zum Thema gemacht, wie soziale Beziehungen zwischen Menschen gestärkt werden oder neu entstehen können und sorgfältig Fallbeispiele recherchiert, wo Menschen mit und durch die Lebensmittel, die sie erzeugen, neue Beziehungen hergestellt haben und pflegen: Zueinander, zum Boden, zu den Kulturpflanzen, die sie kultivieren, zu den Wildpflanzen, die ihre Äcker umgeben, zu den Tieren, die sie halten, zu den Wildtieren, die sich auf ihren Flächen tummeln.

Eine zweite Szene vom Markt. Sie ereignete sich im Oktober letzten Jahres: Bei einem Biogemüse-Stand kaufe ich Kohlrabi. Es ist eine bunte Vielfalt, die ein Mann mittleren Alters anbietet. Rote Rüben, Tomaten und Kohlrabi liegen sorgfältig zu kleinen Grüppchen zusammengestapelt auf einem mit Jute bespannten Tisch. Sie erinnern mich an die Arrangements von Früchten auf den Gemüse- und Obstmärkten, die ich vor vielen Jahren auf einer Reise durch Burkina Faso gesehen hatte. Daneben frische Asia-Salate und frischer Spinat, bereits portionsweise in Papiertüten abgepackt. Auf einer Tafel steht mit Kreide von Hand geschrieben der Name des Betriebs. Ich greife zu einem Kohlrabi und sehe, dass er am Blattansatz voller Läuse ist. Der GemüseMann will ihn mir wieder aus der Hand nehmen und gegen einen lauslosen Kohlrabi umtauschen. Ich meine, das passe schon, die mehlige Kohlblattlaus käme ohnehin in den Bio-Abfall. Er lacht und meint, ob ich Schädlings-Expertin sei. Ich lache und sage, nein, aber Expertin

2 Vgl. Bauchmüller 2020. 
für Bio-Gemüsebau. Ich hätte schon einige Bücher darüber geschrieben. Er meint: »Sie sind aber nicht die Andrea Heistinger?«»Doch« sage ich. Fast ehrfürchtig sagt der Mann, dass alles Gemüse, das er hier verkaufe nach den Anleitungen meiner Bücher angebaut sei. Ich bin gerührt. Das ist das schönste Kompliment, das ich als Autorin bekommen kann. Er erzählt weiter, dass er und seine Frau einen Acker gepachtet hätten. Glücklicherweise werde dieser schon lange biologisch bewirtschaftet. Nun würden sie aber einen Hof suchen, den sie übernehmen könnten.

Beide Markt-Geschichten haben einen gemeinsamen Nenner. Sie erzählen von derselben Ingredienz, die auch alle unsere Fallbeispiele gemeinsam haben: Beziehung. Dialog. Ins Gespräch kommen. Neue Kooperationen finden. In den Beziehungen erwächst für jeden und jede neues Wissen. Ich als Forscherin erfahre, was Menschen, die in der Landwirtschaft tätig sind, gerade beschäftigt, wie sie ihre Betriebe aufbauen, welche Schritte sie in der Vermarktung gehen. Die Betriebsleiter*innen kommen am Markt mit ihren Kund*innen ins Gespräch, bekommen Rückmeldungen, welche Gemüsesorten besonders gut schmecken, und von den Kund"innen Hinweise, wo sie sich bei ihrer Suche nach einem Hof hinwenden könnten oder Unterstützung beim Marketing.

Ich fahre von der Stadt aufs Land, ziehe mich hier für drei Tage zum Schreiben zurück. Im Dorf ist es ruhig. Nebel liegt über der Landschaft. Ein gutes Wetter zum Schreiben. Heidemaries Tulpe steht neben mir. Argument um Argument, Satz und Satz aneinanderreihen, wie Schritt um Schritt, um auch, wenn sich der Weitblick für Momente entzieht, den Weg unter den Füßen nicht zu verlieren. Ich hatte vergessen, mein Telefon auszuschalten. Es läutet. Eine Journalistin einer österreichischen Tageszeitung ruft an und bittet um ein Interview zum Thema Hofübergabe außerhalb der Familie. Ich verweise sie auf die Vermittlungsplattform Perspektive Landwirtschaft und eine Kollegin, die dort arbeitet. Dann eine Nachricht auf meinem Handy: Ein befreundeter Bauer - er ist auch Obmann eines Bauernverbands und kennt die Szene daher gut - schickt mir eine Sterbeanzeige eines Kollegen, ein 61-jähriger Bauer, der »sein Leben in Gottes Hand gegeben hat «. So steht es auf der Sterbeanzeige. Ich erinnere mich an ein Gespräch mit ihm, das wir vor 
ein paar Monaten geführt hatten. Damals erzählte er von elf Bauern, die er persönlich gekannt hat, die sich das Leben genommen hätten aus Verzweiflung über die - ökonomisch wie sozial aussichtslos empfundene - Situation auf ihren Höfen. Kurz darauf läutet das Telefon wieder. Ein Journalist, der eine Fernsehserie dreht über Menschen, die sich auf den Weg machen, ihre Lebensmittel selbst anzubauen, bittet mich, ob ich beim Dreh für die nächsten Folgen dabei sein könnte, um einen Mann bei seinen nächsten Schritten auf diesem Weg zur Selbstversorgung zu beraten. Ich erfahre, dass der Mann seinen Job an den Nagel gehängt hätte. Ich frage nach, welchen. Er hätte ein europäisches Pharmaunternehmen, das in der Organtransplantation tätig ist, in Asien vertreten. Nun hätte sich der Mann einen kleinen Hof gekauft. Dieser liegt in der Nähe der Region, in der wir unser Forschungsprojekt durchgeführt hatten. Ich kenne die Gegend daher gut. Ich sage einem Termin in einem Monat zu. Ich drehe mein Telefon ab und wende mich dem Schreiben zu. 